\title{
Development, Implementation, and Effectiveness of a Self-sustaining, Web-Based LGBTQ+ National Platform: A Framework for Centralizing Local Health Care Resources and Culturally Competent Providers
}

\author{
Dustin Z Nowaskie, MD \\ Department of Psychiatry, Indiana University School of Medicine, Indianapolis, IN, United States
}

\author{
Corresponding Author: \\ Dustin Z Nowaskie, MD \\ Department of Psychiatry \\ Indiana University School of Medicine \\ 355 W 16th Street, \#2364 \\ Indianapolis, IN, 46202 \\ United States \\ Phone: 13179637307 \\ Email: dznowaskie@gmail.com
}

\begin{abstract}
Background: The lesbian, gay, bisexual, transgender, queer, and other sexual and gender minority (LGBTQ+) population has long faced substantial marginalization, discrimination, and health care disparities compared to the cisgender, heterosexual population. As the etiology of such disparities is multifaceted, finding concrete solutions for LGBTQ+ health care equity is challenging. However, the internet may offer the space to initiate an effective model.

Objective: In an effort to make LGBTQ+ public resources and culturally competent providers transparent, modernize medical education, and promote cultural competency, OutCare Health-a nonprofit 501(c)(3) multidisciplinary, multicenter web-based platform-was created.

Methods: The organization employs a cyclic, multidimensional framework to conduct needs assessments, identify resources and providers, promote these efforts on the website, and educate the next generation of providers. LGBTQ+ public health services are identified via the internet, email, and word of mouth and added to the Public Resource Database; culturally competent providers are recruited to the OutList directory via listservs, medical institutions, local organizations, and word of mouth; and mentors are invited to the Mentorship Program by emailing OutList providers. These efforts are replicated across nearly 30 states in the United States.

Results: The organization has identified over 500 public health organizations across all states, recognized more than 2000 OutList providers across all states and 50 specialties, distributed hundreds of thousands of educational materials, received over 10,000 monthly website visits (with $83 \%$ unique viewership), and formed nearly 30 state-specific teams. The total number of OutList providers and monthly website views has doubled every 12-18 months. The majority of OutList providers are trained in primary, first point-of-care specialties such as family medicine, infectious disease, internal medicine, mental health, obstetrics and gynecology, and pediatrics.

Conclusions: A web-based LGBTQ+ platform is a feasible, effective model to identify public health resources, culturally competent providers, and mentors as well as provide cultural competency educational materials and education across the country. Such a platform also has the opportunity to reach self-perpetuating sustainability. The cyclic, multidisciplinary, multidimensional, multicenter framework presented here appears to be pivotal in achieving such growth and stability. Other organizations and medical institutions should heavily consider using this framework to reach their own communities with high-quality, culturally competent care for the LGBTQ+ population.
\end{abstract}

(JMIR Form Res 2021;5(9):e17913) doi: 10.2196/17913 


\section{KEYWORDS}

cultural competency; disparities; e-health; healthcare; internet; LGBTQ+; online platform; providers; resources; eHealth; health care

\section{Introduction}

\section{Background}

The lesbian, gay, bisexual, transgender, queer, and other sexual and gender minority (LGBTQ+) population has long confronted substantial stigma and discrimination within public and health care settings [1,2]. Numerous studies have revealed that LGBTQ+ people are more likely to endure health care disparities and have poorer physical and mental health outcomes than their cisgender, heterosexual counterparts [3-5].

The etiology of such LGBTQ+ disparities is multifaceted. Upwards of $40 \%$ of LGBTQ+ patients experience health care discrimination such as stigmatizing attitudes, refusal of needed medications, and verbal and physical violence [1]. These experiences then lead to postponements and avoidances of routine and urgent care due to anticipation and fear of reliving such stigma $[1,2,6]$. Likewise, the LGBTQ+ population faces more financial barriers to health care than the cisgender, heterosexual population $[7,8]$.

Health care professionals are stationed to both understand these health care complexities as well as intervene when appropriate to alleviate and prevent poor health outcomes. However, many students and providers have been shown to display both explicit and implicit biases $[9,10]$ and discriminatory attitudes $[1,2,11]$, infrequently collect sexual orientation and gender identity information [12-14], and demonstrate shortcomings in education and cultural competency [13-16]. Notably, the quality of LGBTQ+ medical education and the amount of time spent on it has improved only marginally since the 1990s [17], as medical students in 2009-2010 received a median of only five hours of "fair" LGBTQ+ education across their four years of training [18].

Finding concrete solutions for LGBTQ+ health care disparities is challenging. Identifying methods to eliminate discriminatory health care encounters may lead to better health outcomes for LGBTQ+ patients. Institutional endeavors such as increasing formal LGBTQ+ education and curricular reform have shown promising benefits for provider knowledge and attitudinal awareness [19]; however, these educational initiatives, at this time, are locally concentrated and are not standardized or universal. When considering a national solution for LGBTQ+ health equity, the internet may offer the space to initiate an effective model. Past research has shown that LGBTQ+ people use social media and online sources at a higher rate than cisgender, heterosexual individuals [20]. Additionally, the internet serves as an important avenue for sexual expression and health information gathering for LGBTQ+ people [21-23]. Therefore, a national online platform that serves the LGBTQ+ population has the potential to alleviate health care disparities by improving LGBTQ+ health care equality and equity. For example, an online platform affords an excellent opportunity to increase the following: (1) visibility and accessibility of culturally competent care by identifying vetted public resources, providers, and mentors; (2) awareness and appreciation of health care disparities and gaps in provider knowledge by conducting evidence-based academic research; and (3) cultural competency by training the current and next generation of providers.

\section{Objectives}

In an effort to make LGBTQ+ public resources and culturally competent providers transparent, modernize medical education, and promote cultural competency, OutCare Health [24]-a nonprofit 501(c)(3), multidisciplinary, multicenter online platform —was created. Ever since its foundation and initiation, the organization's overarching goals include health care equality and equity for all people regardless of sexual orientation, gender identity, race, ethnicity, socioeconomic status, and other social classifications; access to health care information; collaboration among health care providers and organizations; and a broad community of support for the LGBTQ+ population. Particular objectives include the following: (1) increasing visibility of public health resources and culturally competent providers for the general public; (2) providing medical education and consultation for curricular reform; and (3) creating and distributing educational materials, providing cultural competency trainings, and hosting seminars and conferences for health care providers.

\section{Methods}

OutCare Health was founded in May 2015. The organization employs a cyclic, multidimensional framework to conduct needs assessments, identify resources and providers, promote these efforts on the website, and educate the next generation of providers. For instance, needs assessments, such as evaluating LGBTQ+ patients' satisfaction with medical care [25] and characterizing providers' [13,26,27] and students' [28,29] attitudes, practices, and knowledge, through self-reported surveys are conducted at local and national levels. At the same time, LGBTQ+ public health services are identified via the internet, email, and word of mouth and added to the Public Resource Database; culturally competent providers are recruited to the OutList directory via listservs, medical institutions, local organizations, and word of mouth; and mentors (who provide consultation on school, career, research, and/or other academic pursuits for students, staff, and/or faculty) are invited to the Mentorship Program by emailing OutList providers. Cultural competency trainings are then delivered in person locally and online nationally to fill gaps in LGBTQ+ clinical preparedness, attitudinal awareness, and basic knowledge. Trainings incorporate both clinical (eg, terminology and disparities) and nonclinical (eg, stigma, microaggressions, and how to create welcoming environments) components. Additionally, state-specific team members champion the groundwork for change by creating and distributing educational materials, such as brochures, references, and referrals, to students, faculty, staff, providers, public organizations, and health care systems as well as by promoting the Public Resource Database, OutList, and 
Mentorship Program locally. Members also meet with curriculum committees to implement educational reform. Although this framework is operated at local levels by state-specific teams, the online organization serves as a centralized source for all of these social and public health efforts.

\section{Results}

The organization's impact to date includes the following: identifying over 500 public health organizations across all states on the Public Resource Database, recognizing more than 2000 culturally competent providers across all states and 50 specialties on the OutList, distributing hundreds of thousands of educational materials, receiving over 10,000 monthly website visits (with $83 \%$ unique viewership), and forming nearly 30 state-specific teams. Both the total number of OutList providers and monthly website views have doubled every 12-18 months (Figure 1, Figure 2). Within the OutList, there are more primary, first point-of-care specialties represented than other health care specialties; these include family medicine $(n=370)$, infectious disease $(n=86)$, internal medicine $(n=218)$, mental health and counseling $(n=731)$, obstetrics and gynecology $(n=161)$, pediatrics $(n=137)$, psychiatry $(n=78)$, and social work $(n=118)$.

Figure 1. OutCare Health OutList growth. Growth of the total number of culturally competent providers in OutCare Health's OutList provider directory. The number of culturally competent providers was calculated via online submission count and Google Analytics. Data between OutCare Health's initiation (May 2015) and April 2017 were intermittently collected.

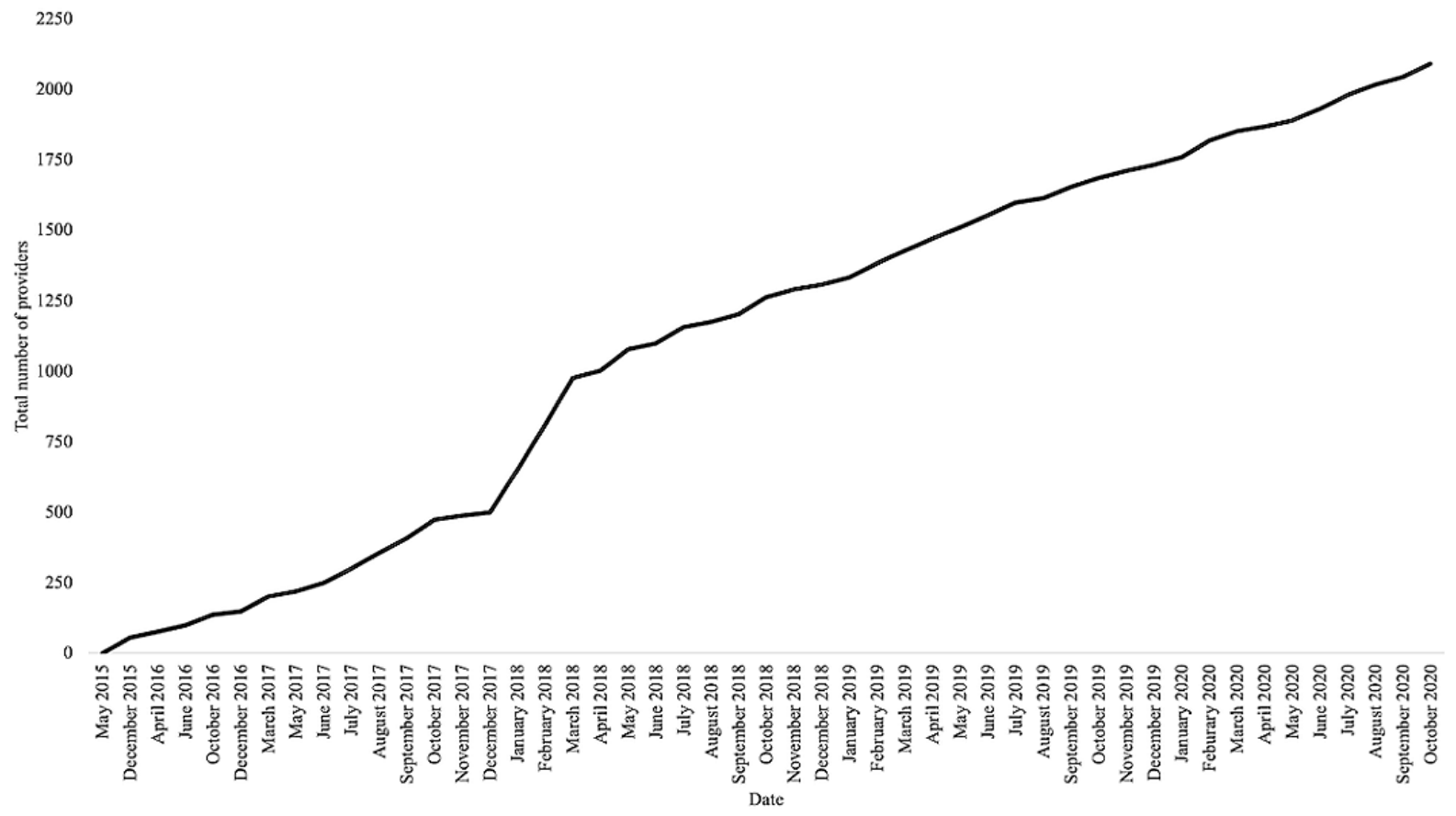


Figure 2. OutCare Health website's viewership growth. Growth of monthly website views on OutCare Health. The number of monthly views was calculated via Google Analytics (83\% are unique viewers). Data were not collected between OutCare Health's initiation (May 2015) and July 2016.

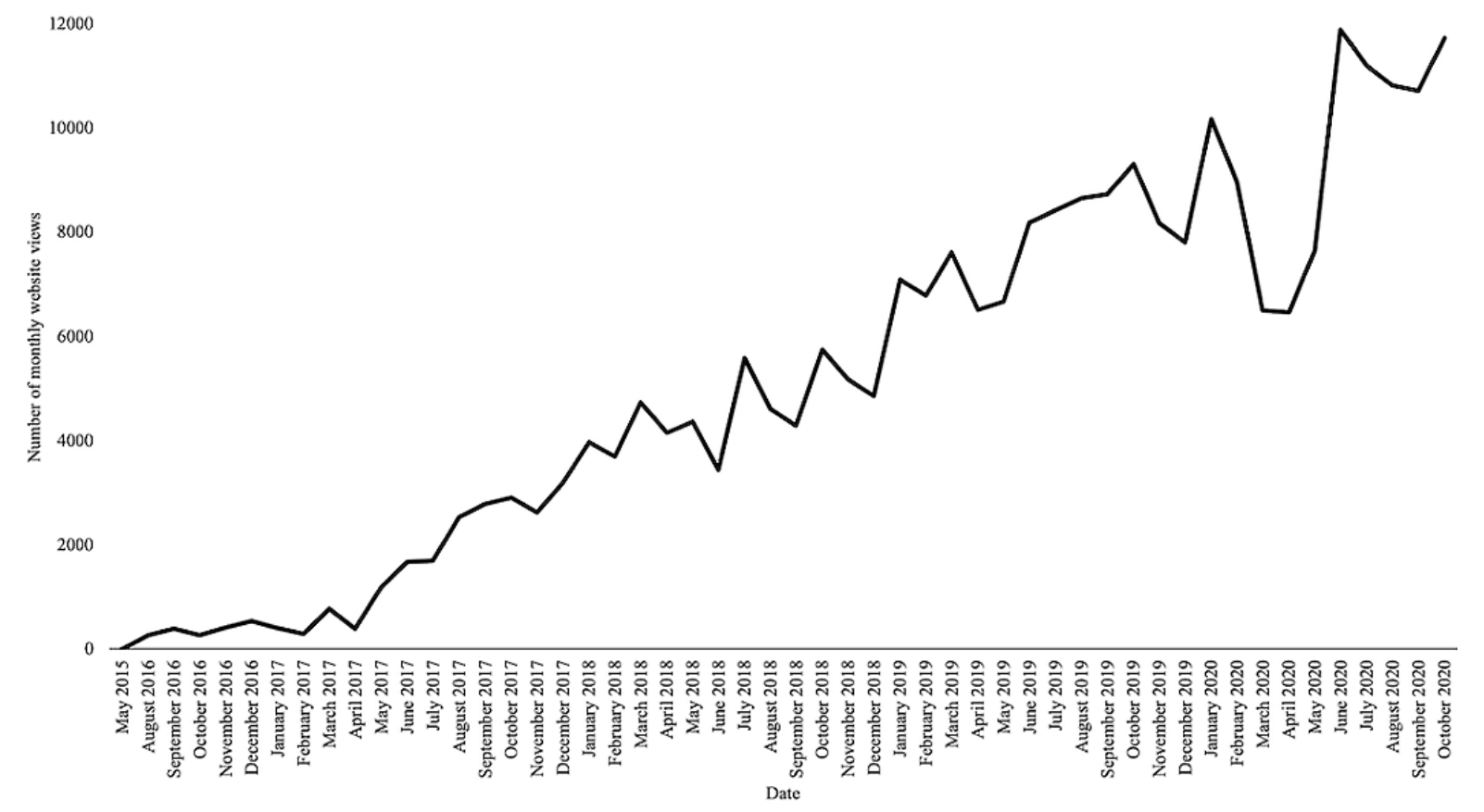

\section{Discussion}

\section{Principal Findings}

Health care disparities are substantially prevalent among the LGBTQ+ population. Many studies have demonstrated that health care providers can express negative attitudes and erroneous beliefs about LGBTQ+ people. Incorrect assumptions can lead to inadequate care if providers do not have the awareness and knowledge of how LGBTQ+ cultural factors impact health. Thus, LGBTQ+ health care equity requires providers who will impart and advocate for the care of and respect for the LGBTQ+ population in a culturally competent manner while providing safe spaces.

In an effort to make LGBTQ+ resources transparent, modernize medical education, and promote cultural competency, the nonprofit organization OutCare Health implements an online cyclic, multidisciplinary, multidimensional, multicenter framework to foster such change. Longitudinal projects, such as identifying public health resources, culturally competent providers, and mentors, has allowed the organization to promote awareness and up-to-date information and education so that the current and future health care workforce can deliver better LGBTQ+ care. The growth of the Public Resource Database, OutList, Mentorship Program, and website viewership highlights the necessity of this valuable information for public and health care communities. Of note, while there are some continued efforts to increase use of these databases via direct communication, the organization has become a self-sustaining online platform. For example, of the monthly viewers, a high percentage are new visitors to the website. Likewise, the majority of newly enlisted OutList providers practice in states that have not been directly marketed to as of yet. Given the disproportionate primary care and mental health disparities that LGBTQ+ people face, the growth of the OutList parallels this need in specialty-specific ways (ie, the majority of OutList providers are trained within family medicine, internal medicine, mental health, obstetrics and gynecology, and pediatrics). Sustainability is also achieved through providers' ability to update and maintain their own OutList profiles. To complement this sustainability, the organization's state-specific teams identify resources and providers within their respective states and create self-sustaining public and health care presences as well. Consequently, OutCare Health and its resources are reaching new members and spreading across communities organically. However, providing these LGBTQ+ services to particular areas and populations, such as rural communities and people without access to the internet, has proven challenging. Future efforts include collaborations with large national health care organizations as well as local LGBTQ+ public groups to improve community outreach, dissemination of this information, and access to care.

\section{Conclusions}

Health care equity for the LGBTQ+ population is both a community and institutional endeavor. An online LGBTQ+ platform is a feasible, effective model to identify public health resources, culturally competent providers, and mentors as well as provide culturally competent educational materials and education across the country. Such a platform also has the opportunity to reach self-perpetuating sustainability. The cyclic, multidisciplinary, multidimensional, multicenter framework presented here appears to be pivotal in achieving such growth and stability. Other local organizations and medical institutions should heavily consider recognizing LGBTQ+ health care and 
associated disparities as a multifaceted health concern. By implementing the framework discussed here, these groups would likely be effective in reaching their own and surrounding communities with high-quality, culturally competent care for the LGBTQ+ population.

\section{Acknowledgments}

The author herein wishes to acknowledge and thank Indiana University School of Medicine Diversity Affairs and equalityMD, including Justin Ayars, Jesse LaVancher, and Rachel Amin, for supporting publication costs.

\section{Conflicts of Interest}

The corresponding author (DZN) of this publication is the founder, owner, and president of the non-profit 501(c)(3) organization OutCare Health. No conflicts of interest or competing financial interests exist for the author of this research.

\section{References}

1. Ayhan CHB, Bilgin H, Uluman OT, Sukut O, Yilmaz S, Buzlu S. A Systematic Review of the Discrimination Against Sexual and Gender Minority in Health Care Settings. Int J Health Serv 2020 Jan;50(1):44-61. [doi: 10.1177/0020731419885093] [Medline: 31684808]

2. Casey LS, Reisner SL, Findling MG, Blendon RJ, Benson JM, Sayde JM, et al. Discrimination in the United States: Experiences of Lesbian, Gay, Bisexual, Transgender, and Queer Americans. Health Serv Res 2019 Dec;54(S2):1454-1466. [doi: 10.1111/1475-6773.13229] [Medline: 31659745$]$

3. Hafeez H, Zeshan M, Tahir MA, Jahan N, Naveed S. Health Care Disparities Among Lesbian, Gay, Bisexual, and Transgender Youth: A Literature Review. Cureus 2017 Apr 20;9(4):e1184 [FREE Full text] [doi: 10.7759/cureus.1184] [Medline: 28638747]

4. Lunn MR, Cui W, Zack MM, Thompson WW, Blank MB, Yehia BR. Sociodemographic Characteristics and Health Outcomes Among Lesbian, Gay, and Bisexual U.S. Adults Using Healthy People 2020 Leading Health Indicators. LGBT Health 2017 Aug;4(4):283-294. [doi: 10.1089/lgbt.2016.0087] [Medline: 28727950]

5. Wallace B, Santacruz E. Health Disparities and LGBT Populations. In: Ruth R, Santacruz E, editors. LGBT Psychology and Mental Health: Emerging Research and Advances. Santa Barbara, CA: Praeger; 2017:177-196.

6. Romanelli M, Hudson KD. Individual and Systemic Barriers to Health Care: Perspectives of Lesbian, Gay, Bisexual, and Transgender Adults. Am J Orthopsychiatry 2017;87(6):714-728. [doi: 10.1037/ort0000306] [Medline: 29154611]

7. Gonzales G, Dedania R, Driscoll R. Health Insurance Coverage and Access to Care Among US-Born and Foreign-Born Sexual Minorities. J Immigr Minor Health 2019 Jun;21(3):540-548. [doi: 10.1007/s10903-018-0774-x] [Medline: 29946865]

8. Gonzales G, Henning-Smith C. Barriers to Care Among Transgender and Gender Nonconforming Adults. Milbank Q 2017 Dec;95(4):726-748. [doi: 10.1111/1468-0009.12297] [Medline: 29226450]

9. Burke SE, Dovidio JF, Przedworski JM, Hardeman RR, Perry SP, Phelan SM, et al. Do Contact and Empathy Mitigate Bias Against Gay and Lesbian People Among Heterosexual First-Year Medical Students? A Report from the Medical Student CHANGE Study. Acad Med 2015 May;90(5):645-651. [doi: 10.1097/acm.0000000000000661] [Medline: 25674910]

10. Sabin JA, Riskind RG, Nosek BA. Health Care Providers' Implicit and Explicit Attitudes Toward Lesbian Women and Gay Men. Am J Public Health 2015 Sep;105(9):1831-1841. [doi: 10.2105/ajph.2015.302631] [Medline: 26180976]

11. Aleshire ME, Ashford K, Fallin-Bennett A, Hatcher J. Primary Care Providers' Attitudes Related to LGBTQ People: A Narrative Literature Review. Health Promot Pract 2019 Mar;20(2):173-187. [doi: 10.1177/1524839918778835] [Medline: 29947564]

12. Goldhammer H, Maston ED, Kissock LA, Davis JA, Keuroghlian AS. National Findings from an LGBT Healthcare Organizational Needs Assessment. LGBT Health 2018 Dec;5(8):461-468. [doi: 10.1089/lgbt.2018.0118] [Medline: 30383473]

13. Nowaskie DZ, Sowinski JS. Primary Care Providers' Attitudes, Practices, and Knowledge in Treating LGBTQ Communities. J Homosex 2019;66(13):1927-1947. [doi: 10.1080/00918369.2018.1519304] [Medline: $\underline{30265839}$ ]

14. Shetty G, Sanchez JA, Lancaster JM, Wilson LE, Quinn GP, Schabath MB. Oncology Healthcare Providers' Knowledge, Attitudes, and Practice Behaviors Regarding LGBT Health. Patient Educ Couns 2016 Oct;99(10):1676-1684. [doi: 10.1016/j.pec.2016.05.004] [Medline: 27161166]

15. Hayes V, Blondeau W, Bing-You RG. Assessment of Medical Student and Resident/Fellow Knowledge, Comfort, and Training With Sexual History Taking in LGBTQ Patients. Fam Med 2015 May;47(5):383-387 [FREE Full text] [Medline: 25905882]

16. Khalili J, Leung LB, Diamant AL. Finding the Perfect Doctor: Identifying Lesbian, Gay, Bisexual, and Transgender-Competent Physicians. Am J Public Health 2015 Jun;105(6):1114-1119. [doi: 10.2105/ajph.2014.302448] [Medline: 25880937]

17. Wallick MM, Cambre KM, Townsend MH. How the Topic of Homosexuality is Taught at U.S. Medical Schools. Acad Med 1992 Sep;67(9):601-603. [doi: 10.1097/00001888-199209000-00013] [Medline: 1520420] 
18. Obedin-Maliver J, Goldsmith ES, Stewart L, White W, Tran E, Brenman S, et al. Lesbian, Gay, Bisexual, and Transgender-related Content in Undergraduate Medical Education. JAMA 2011 Sep 07;306(9):971-977. [doi: 10.1001/jama.2011.1255] [Medline: 21900137]

19. Sekoni AO, Gale NK, Manga-Atangana B, Bhadhuri A, Jolly K. The Effects of Educational Curricula and Training on LGBT-specific Health Issues for Healthcare Students and Professionals: A Mixed-Method Systematic Review. J Int AIDS Soc 2017 Jul 19;20(1):21624. [doi: 10.7448/ias.20.1.21624] [Medline: 28782330]

20. Seidenberg AB, Jo CL, Ribisl KM, Lee JG, Buchting FO, Kim Y, et al. A National Study of Social Media, Television, Radio, and Internet Usage of Adults by Sexual Orientation and Smoking Status: Implications for Campaign Design. Int J Environ Res Public Health 2017 Apr 21;14(4):450. [doi: 10.3390/ijerph14040450] [Medline: 28430161]

21. DeHaan S, Kuper LE, Magee JC, Bigelow L, Mustanski BS. The Interplay between Online and Offline Explorations of Identity, Relationships, and Sex: A Mixed-Methods Study with LGBT Youth. J Sex Res 2013;50(5):421-434. [doi: 10.1080/00224499.2012.661489] [Medline: 22489658]

22. Lee JH, Giovenco D, Operario D. Patterns of Health Information Technology Use according to Sexual Orientation among US Adults Aged 50 and Older: Findings from a National Representative Sample-National Health Interview Survey 2013-2014. J Health Commun 2017 Aug;22(8):666-671. [doi: 10.1080/10810730.2017.1341566] [Medline: 28749748]

23. Mitchell KJ, Ybarra ML, Korchmaros JD, Kosciw JG. Accessing Sexual Health Information Online: Use, Motivations and Consequences for Youth with Different Sexual Orientations. Health Educ Res 2014 Feb;29(1):147-157. [doi: 10.1093/her/cyt071] [Medline: 23861481]

24. OutCare Health: The Future of LGBTQ+ Healthcare is Here. URL: http://www.outcarehealth.org [accessed 2020-11-01]

25. Nowaskie DZ, Fogel RS, Fogel JM. Impact on Patient Satisfaction and Importance of Medical Intake and Office Staff in a Multidisciplinary, One-stop Shop Transgender Program in Indianapolis, Indiana. J Multidiscip Healthc 2019 Aug 15;12:665-673. [doi: 10.2147/jmdh.s216969] [Medline: 31616155]

26. Nowaskie D. A national survey of U.S. psychiatry residents' LGBT cultural competency: The importance of LGBT patient exposure and formal education. Journal of Gay \& Lesbian Mental Health 2020 Jul 01;24(4):375-391. [doi: $10.1080 / 19359705.2020 .1774848]$

27. Nowaskie DZ, Sewell DD. Assessing the LGBT cultural competency of dementia care providers. Alzheimers Dement (N Y) 2021;7(1):e12137 [FREE Full text] [doi: 10.1002/trc2.12137] [Medline: 33614899]

28. Nowaskie DZ, Patel AU, Fang RC. A Multicenter, Multidisciplinary Evaluation of 1701 Healthcare Professional Students' LGBT Cultural Competency: Comparisons between Dental, Medical, Occupational Therapy, Pharmacy, Physical Therapy, Physician Assistant, and Social Work Students. PLoS One 2020 Aug 13;15(8):e0237670. [doi: 10.1371/journal.pone.0237670] [Medline: 32790797]

29. Nowaskie DZ, Patel AU. How Much is Needed? Patient Exposure and Curricular Education on Medical Students' LGBT Cultural Competency. BMC Med Educ 2020 Dec 04;20(1):490. [doi: 10.1186/s12909-020-02381-1] [Medline: 33276769]

\section{Abbreviations}

LGBTQ+: lesbian, gay, bisexual, transgender, queer, and other sexual and gender minorities

Edited by R Kukafka, G Eysenbach; submitted 21.01.20; peer-reviewed by J Constantin, C Escobar-Viera, M Montgomery; comments
to author 26.10.20; revised version received 13.11.20; accepted 02.08.21; published 22.09.21
Please cite as:
Nowaskie DZ
Development, Implementation, and Effectiveness of a Self-sustaining, Web-Based LGBTQ+ National Platform: A Framework for
Centralizing Local Health Care Resources and Culturally Competent Providers
JMIR Form Res $2021 ; 5(9):$ :17913
URL: $\underline{\text { https://formative.jmir.org/2021/9/e17913 }}$
doi: $10.2196 / 17913$
PMID:

CDustin Z Nowaskie. Originally published in JMIR Formative Research (https://formative.jmir.org), 22.09.2021. This is an open-access article distributed under the terms of the Creative Commons Attribution License (https://creativecommons.org/licenses/by/4.0/), which permits unrestricted use, distribution, and reproduction in any medium, provided the original work, first published in JMIR Formative Research, is properly cited. The complete bibliographic information, a link to the original publication on https://formative.jmir.org, as well as this copyright and license information must be included. 